\title{
Challenges of Canteen Intervention for Diabetes Prevention in the Worksite Set Up of Eastern Nepal
}

\author{
Prajjwal Pyakurel, ${ }^{1}$ Ranjana Gurung, ${ }^{2}$ Hom Bahadur Parajuli ${ }^{2}$ \\ ${ }^{1}$ School of Public Health and Community Medicine, B.P.Koirala Institute of Health Sciences, Dharan, Nepal, ${ }^{2}$ Worksite \\ Intervention Project for the Prevention of Diabetes in Nepal, B.P.Koirala Institute of Health Sciences, Dharan, Nepal.
}

\section{INTRODUCTION}

Type-2 diabetes is a major, non-communicable disease with increasing prevalence at a global level. ${ }^{1}$ The number of people with diabetes has risen from 108 million in 1980 to 422 million in 2014. Diabetes prevalence has been rising more rapidly in middle- and low-income countries. ${ }^{2}$ In Nepal, there is a lack of reliable and representative data on the prevalence of type 2 diabetes. However, various small studies from different parts of the country have shown prevalence rates ranging from $6.3 \%$ to $8.5 \%{ }^{3}$ The burden of diabetes in terms of disability adjusted life years has increased almost 100\% from 1990 to $2010 .{ }^{4}$ A pilot study in an industrial setting of eastern Nepal showed a prevalence of $4 \%$ diabetes and $31 \%$ pre-diabetes among adult employees. ${ }^{5}$

The prevention of type 2 diabetes through lifestyle intervention has been established by several clinical trials. ${ }^{6}$ The US Diabetes Prevention Program clinical trial demonstrated that structured lifestyle interventions - such as training people with prediabetes to achieve modest weight loss through diet and physical activity-reduced three-year diabetes incidence by 58 percent. $^{\text {? }}$

Worksite-based interventions can facilitate healthy lifestyle choices by providing resources at a place and time where individuals spend much of their working hours and interact within a socially supportive environment. Worksite-based health promotion programs have shown positive impacts on employees and worksites; a metanalysis (30) reported significant positive improvements in fasting glucose, lower absenteeism and job stress and a worksite-based education program to improve employee diets resulted in significant improvements in diet quality. ${ }^{8,9}$ Worksite wellness programs and intervention programs targeting diabetes prevention and weight loss have also shown positive effects on both mental (increased feelings of calmness, happiness, and ability to cope with stress) and physical (improvements in diet and physical activity behaviors, aerobic fitness, anthropometry, blood pressure, lipid profiles, plasma glucose) health. ${ }^{10,11}$

To apply similar intervention in Nepal set up we screened 350 permanent workers in Hulas wire industry in Morang district of eastern Nepal. Hula wire industry was chosen as a study site because previous study done by author himself in 2012 showed high prevalence diabetic (4\%) and prediabetic (31\%) among these population. ${ }^{5}$

To start up the screening we administered a brief screening questionnaire. Those who were diabetic and hypertensive and under medication previously were excluded from the study. Blood sample for Fasting blood sugar and glycated hemoglobin (HbAlc) were taken for those who were found eligible for the study. It was found that among those screened 110 were found to be pre-diabetic $(\mathrm{HbA} 1 \mathrm{C}=5.7$ to 6.4$)$.

After completion of screening we waited for a control period for 6 months. Now we set up to start a canteen intervention program in three canteens of the industry. Canteen intervention program will comprise of replacing unhealthy food with healthy food without replacing the price of the food.

We anticipate to face many challenges during our canteen intervention phase some of which includes: 1. Improve physical facility in the canteens: increase dining space, improve cleanliness, remodeling kitchen area.

2. Increase access to healthy foods in canteen: Adding salad and fruit corner, whole grains and its products, low fat dairy.

3. Displaying information, education and communication board in the canteens: Display of healthy food options in the form of posters and/or

Correspondence: Dr. Prajjwal Pyakurel, School of Public Health and Community Medicine, B. P. Koirala Institute of Health Sciences, Dharan, Nepal. Email: prazzwal@gmail.com. Phone: +977-9813865905. DOI:10.3126/ jcmsn.v14i4.22244. Article received: 2018-12-05. Article accepted: 2018-12-23. 


\section{Pyakurel et al. Challenges of Canteen Intervention for Diabetes Prevention in the Worksite..}

paintings in the cafeteria walls and displaying of color coding system to denote food with different calorie intake.

4. Training of cafeteria staffs: hygiene, healthy foods options, cooking healthy.

5. Replacing white rice with brown rice.

However, if the program is shown to be effective at these worksites, the results of this study will be used to recommend and disseminate a sustainable environment and lifestyle interventions at worksites to improve the health of workers, other Nepali worksites, and to Nepal's national program for prevention and control of non-communicable disease. Furthermore, lessons from this study can be used to make recommendations or plan studies of similar worksite programs in the U.S. and other settings outside of Nepal.

\section{Conflict of Interest: None}

How effective were lifestyle interventions in real -world settings that were modeled on the diabetes prevention program? Health Aff. 2012;31(1):67-75.

8. Holdsworth M, Haslam C. A review of point-ofchoice nutrition labeling schemes in the workplace, public eating places and universities. J Hum Nutr Diet 1998;11:423-445.

9. Dugdill L, Brettle A, Hulme C, McCluskey S, Long AF. Workplace physical activity interventions: a systematic review. Int J Work Heal Manag [Internet]. 2008;1(1):20. Available $\mathrm{f} \quad \mathrm{r} \quad \mathrm{o} \quad \mathrm{m}$

http://0proquest.umi.com.library.ecu.edu.au/ p q d w e b ? d i d = 1574087991 $\& \mathrm{Fmt}=7 \& \mathrm{client} \mathrm{Id}=7582 \& \mathrm{RQT}=309 \& \mathrm{VNa}$ $\mathrm{me}=\mathrm{PQD}$

10. Abraham C, Graham-Rowe E. Are worksite interventions effective in increasing physical activity? A systematic review and meta-analysis. Health Psychol Rev [Internet]. 2009;3(May 2015):37-41. Available from:http:// dx.doi.org/10.1080/17437190903151096

11. Proper KI, Koning M, van der Beek AJ, Hildebrandt VH, Bosscher RJ, van Mechelen W. The effectiveness of worksite physical activity programs on physical activity, physical fitness, and health. Clin J Sport Med [Internet]. 2003;13 (2):106-17. Available from: http:// onlinelibrary.wiley.com/o/cochrane/cldare/ articles/DARE12003009495/frame.html\nhttp:// www.ncbi.nlm.nih.gov/pubmed/12629429

Citation: Pyakurel P, Gurung R, Parajuli HB. Challenges of Canteen Intervention for Diabetes Prevention in the Worksite Set Up of Eastern Nepal. JCMS Nepal. 2018;14(4):232-3. 